\title{
A multiplicative autoregressive integrated moving average model for Kenya's inflation (2000:1 - 2013:12)
}

\author{
Nyabwanga Robert Nyamao \\ Kisii University, School of Pure and Applied Sciences, Department of Statistics and Actuarial Science, Kisii, Kenya
}

Email address:

nyamaonyabwanga@gmail.com

\section{To cite this article:}

Nyabwanga Robert Nyamao. A Multiplicative Autoregressive Integrated Moving Average Model for Kenya's Inflation (2000:1 - 2013:12). Science Journal of Applied Mathematics and Statistics. Vol. 2, No. 6, 2014, pp. 122-129. doi: 10.11648/j.sjams.20140206.14

\begin{abstract}
Using monthly inflation data from January 2000 to December 2013 , we find that SARIMA $(1,1,1)(1,0,1)_{12}$ can represent the data behavior of inflation rate in Kenya well. Based on the selected model, we forecast seven (12) months inflation rates of Kenya outside the sample period (i.e. from January 2014 to December 2014). The observed inflation rates from January to November which were published by Kenya Bureau of Statistics fall within the 95\% confidence interval obtained from the designed model. However, the confidence intervals were wider an indication of high volatility of Kenya's inflation rates.
\end{abstract}

Keywords: Inflation, Forecasting, Box-Jenkins Approach, Multiplicative ARIMA Model, Unit Root Test, ADF Test, Ljung-Box Test

\section{Introduction}

Inflation is a major economic challenge that faces most countries in the world especially underdeveloped and developing countries and is a major focus of economic policy worldwide since it causes global concerns because it can distort economic patterns and can result in the redistribution of wealth when not anticipated. Webster's (2000) defines inflation as the persistent increase in the level of consumer prices or a persistent decline in the purchasing power of money.

According to Mishkin (2008) inflation is the rate at which the general level of prices for goods and services is rising, and, subsequently, purchasing power is falling. Central banks attempt to stop severe inflation, along with severe deflation, in an attempt to keep the excessive growth of prices to a minimum. High inflation levels in many developing countries have been a cause of concern to their central banks. This has led to the adoption of monetary policy frameworks such as inflation targeting to help lower inflation to more sustainable levels. The determinants of inflation are important factors to consider when looking at the different monetary policy frameworks to adopt. One of the major determinants of inflation is exchange rate movements and the degree of sensitivity of domestic prices to these movements.

Inflationary analysis or modeling is one of the most important research areas in monetary planning. This is due to the fact that a high and sustained economic growth in conjunction with low inflation is the central objective of macroeconomic policy. Achieving and maintaining price stability will be more efficient and effective if the causes of inflation and the dynamics of its evolution are well understood. It is a fact that monetary policy-makers and planners worldwide are more interested in stabilizing or reducing inflation through monetary policies (price stability). Inflation is usually defined as a sustained rise in a broadly based index of commodity prices over some period of time, (Fisher et al, 2002).

Major components of this definition are that the rise in prices takes place in a variety of sectors dealing with goods and services; also this increase spans from a rather lengthy period of time rather than two or more quarters. This means that when the price increases, each unit of currency buys fewer goods and services and as a result, inflation is an erosion of the purchasing power, which results in loss in real value in the medium and unit of account in the economy (Stokes, 2009).

Kenya's economy is market-based, with a few state-owned infrastructure enterprises, and maintains a liberalized external trade system. The country is generally perceived as Eastern and central Africa's hub for Financial, Communication and Transportation services. As at May 2010, economic prospects are positive with 4-5\% GDP growth expected, largely because 
of expansions in tourism, telecommunications, transport, construction and a recovery in agriculture.

High inflation has rendered the cost of loanable funds prohibitive. Subsequent high interest rates have in turn prevented productive sectors of the economy from accessing finance for growth and development (FIAS, 2002).

Based on thisbackground the study sought to

i. establish the trend of Kenya's inflation (2000 - 2013)

ii. identify the Multiplicative SeasonalARIMA model that can best be used to forecast Kenya's inflation rates

iii. estimate inflation in the next twelve (12) months of 2014

\section{Literature Review}

According to Mishkin (2008) inflation is the rate at which the general level of prices for goods and services is rising, and, subsequently, purchasing power is falling. Mishkin further asserts that high inflation levels in many developing countries have been a cause of concern to the central bank and has led to the adoption of monetary policy frameworks targeting to help lower inflation to more sustainable levels. On the other hand Akofio-Sowah (2009) defines it as the percentage change in the local currency import prices resulting from a one percent change in the exchange rate between the importing and the exporting country.

For an open economy like Kenya, inflation comes from both internal pressures and external pressures. The external factors results from increase in the world prices of commodities or fluctuation in the real exchange rate. However, the influence of exchange rate on inflation is a function of the exchange rate in the country (Rotichet al, 2007).

Buckman and Mintah (2013) applied Autoregressive Integrated Moving Average (ARIMA) to Model Ghana's monthly inflation from January 1985 to December 2011 and used the model to forecast twelve (12) months inflation for Ghana. Using the Box Jenkins (1976) framework, the autoregressive integrated moving average (ARIMA) was employed to fit the best ARIMA model. The seasonal ARIMA model, SARIMA $(1,1,2)(1,0,1)_{12}$ was chosen as the best fitting from the ARIMA family of models with least Akaike Information Criteria (AIC) of 1156.08 and Bayesian Information Criteria (BIC) of 1178.52. The plots of actual values and the forecasted values of inflation were very close implying that the selected model best fit the data and hence, appropriate for forecasting. The forecast error of 3.4 also gave further evidence that the model selected had very strong predictive power.

Otu et al. (2013) applied SARIMA Models in Modeling and Forecasting Nigeria's Inflation Rates based on monthly rates for the period November 2003 to October 2013 by making use of Box-Jenkins methodology. In this research, $\operatorname{ARIMA}(1,1,1)$ $(0,0,1)_{12}$ model was developed and was used to forecast Nigeria's monthly inflation for the year 2014.

Fritzer et al. (2002) evaluated the performance of VAR and ARIMA models to forecast Austrian HICP inflation. they further investigated whether disaggregate modeling of five subcomponents of inflation is superior to specifications of headline HICP inflation with the aim of finding the adequate VAR and ARIMA specifications that would minimize the 12 months out-of-sample forecasting error. The study established that VAR models outperformed the ARIMA models in terms of forecasting accuracy over the longer projection horizon and that disaggregated approach improves forecasting accuracy substantially for ARIMA models

\section{Materials and Methods}

The time-series data corresponding to monthly observations of the inflation rates' datasets for the time period 2000:1 2013:12 as provided by Kenya Bureau of Statistics were used in the study. The data was fitted to the Seasonal ARIMA model. A time series is said to be seasonal if there exists a tendency for the series to exhibit a periodic behaviour after certain time interval. The usual ARIMA models cannot really cope with seasonal behaviour, it only models time series with trends. Seasonal ARIMA models are formed by including an additional seasonal terms in the ARIMA models and are defined by seven parameters.

Let $\mathrm{X}_{\mathrm{t}}=\left(\mathrm{X}_{1}, \mathrm{X}_{2}, \ldots, \mathrm{X}_{\mathrm{n}}\right)$ be a time series of data. A seasonal ARIMA model with $\mathrm{s}$ observations denoted by

$\operatorname{ARIMA}(p, d, q)(P, D, Q)_{S}$ is given as:

$$
\Phi\left(\mathrm{B}^{\mathrm{S}}\right) \varphi(\mathrm{B})(1-\mathrm{B})^{\mathrm{d}}(1-\mathrm{BS})^{\mathrm{D}} \mathrm{X}_{\mathrm{t}}=\Theta\left(\mathrm{B}^{\mathrm{S}}\right) \theta(\mathrm{B}) \varepsilon_{\mathrm{t}}
$$

Where $\mathrm{B}$ is the lag operator given by $\mathrm{B}_{\mathrm{k}}=\mathrm{X}_{\mathrm{t}}-\mathrm{k} / \mathrm{X}_{\mathrm{t}}$, $\varphi(\mathrm{B})=1-\varphi_{1} \mathrm{~B}^{1}-\varphi_{2} \mathrm{~B}^{2}-\ldots-\varphi_{\mathrm{p}} \mathrm{B}^{\mathrm{p}}$ is an autoregressive (AR) polynomial function of order $p$

$\theta(B)=1+\theta_{1} B^{1}+\theta_{2} B^{2}+\ldots+\theta_{q} B^{q}$ is a moving average (MA) polynomial of order $q$

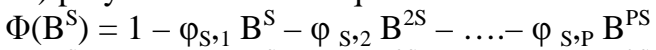

$\Theta\left(\mathrm{B}^{\mathrm{S}}\right)=1+\theta_{\mathrm{S}, 1} \mathrm{~B}^{\mathrm{S}}+\theta_{\mathrm{S}, 2} \mathrm{~B}^{2 \mathrm{~S}}+\ldots+\theta_{\mathrm{S}, \mathrm{Q}} \mathrm{B}^{\mathrm{QS}}$ are seasonal polynomial functions of order $\mathrm{P}$ and $\mathrm{Q}$, respectively, that satisfy the stationarity and invertibility conditions, $d$ is the number of differencing passes needed to stationarize the series, $\mathrm{D}$ is the number of seasonal differences and $\varepsilon_{\mathrm{t}}$ are error terms assumed to be independent identically distributed random variables sampled from a distribution with a mean equal to zero and the variance $\sigma_{2 \varepsilon}$. In time series analyses, the variables $\varepsilon_{\mathrm{t}}$ are commonly referred to as white noises, and they are interpreted as an exogenous effect that the model is not able to explain.

The SARIMA model of inflation rates 2000 to 2013 in Kenya was fitted using the Box-Jenkins modelling approach which emphasizes on four key stages: Model identification; Parameter estimation; Model adequacy checking and model forecasting.

In model identification stage first, the data was examined for possible data patterns. But before that the series of monthly inflation rates was checked for the stationary using both the Kwiatkowski-Phillips-Schmidt-Shin(KPSS) test and the Augmented Dickey Fuller (ADF) test.

For the KPSS test, the hypotheses tested were:

$H_{0}: \sigma_{e}^{2}=0$ (Stationarity) Vs.

$H_{1}: \sigma_{e}^{2}>0$ (Non-stationarity).

The test statistic was given by: 


$$
K P S S=\frac{T^{-2} \sum_{t=1}^{T} \hat{S}_{t}^{2}}{\hat{\tau}^{2}}
$$

Where;

$\hat{S}_{t}^{2}=\sum_{j=1}^{t} \hat{u}_{j}$, and $\hat{u}_{j}$ is the residual of the regression of $\mathrm{Xt}$ on Dt.

$\hat{\tau}^{2}$ is the consistent estimate of the long-run variance of $\mathrm{u}_{\mathrm{t}}($ Kwiatkowski et al. 1992)

Under the ADF test, the unit root test is carried out under the null hypothesis $\gamma=0$ against the alternative hypothesis of $\gamma<0$. the value for the test statistic is computed by the formula;

Given that $\Delta \mathrm{Xt}=\mathrm{ut}$, where $\Delta \mathrm{Xt}=\mathrm{Xt}-\mathrm{Xt}-1$, which can alternatively be expressed as

$\Delta \mathrm{Xt}=\gamma X_{t-1}+\mu+\lambda t+u_{t}$ with $\mu=\lambda=0$, and $=\varphi-1$, then

$$
A D F_{\tau}=\frac{\widehat{\gamma}}{\operatorname{SE}(\widehat{\gamma})}
$$

If the test statistic is less than the critical value, then the null hypothesis of $\gamma=0$ is rejected implying that no unit root is present (Dickey \& Fuller, 1981).

The Autocorrelation Function (ACF) and the Partial Autocorrelation Function (PACF) collelograms were observed to determine the possible model parameters. The ACF measures the amount of linear dependence between observations in a time series that are separated by a lag $\mathrm{k}$. The PACF plot helps to determine how many autoregressive terms are necessary to reveal one or more of the following characteristics: time lags where high correlations appear, seasonality of the series, trend either in the mean level or in the variance of the series.

The Akaike information criterion (AIC) and Bayesian Information Criteria (BIC) were employed to compare the goodness-of-fit of different models so as to determine the best fit model. Lower AIC values indicate better fit. The models for the AIC and BIC values are given as:

$$
\begin{gathered}
A I C=2 k-2 \log (L) \\
B I C=-2 \log (L)+k \log (n)+k \log (n)
\end{gathered}
$$

Where;

$\mathrm{k}=$ Number of parameters in the statistical model $=$ $\mathrm{p}+\mathrm{q}+\mathrm{P}+\mathrm{Q}+1$

$\mathrm{L}=$ maximized value of the likelihood function

$\mathrm{n}=$ Number of observations

The adequacy of the model was verified by plots of the histogram and an autocorrelation (ACF) of the standardized residuals and the Ljung-Box test, which is a test for hypotheses of no correlation across a specified number of time lags. ACF of the residuals and Ljung-Box statistics are useful for testing the randomness of the residuals.

\section{Results}

\subsection{Statistical Parameters of Historical Inflation Data}

The inflation rates for the 168 months of data ranged from a minimum of 0.461 to a maximum of 19.716.Mean inflation was $8.50 \%$ with a SE of 0.381 . The sample standard deviation, $\mathrm{S}$ is 4.932 which indicate that the dispersal of the data points from the mean of 8.5 is large. The skewness index of 0.52 indicates that the inflation data is positively skewed however the departure from a normal distribution is small.

Table 1. Statistical parameters for Kenya'sinflation data.

\begin{tabular}{lllllll}
\hline Variable & N & Mean & SE Mean & StDev & Skew & Kurt \\
\hline INFRATE & 168 & 8.50 & 0.38 & 4.93 & 0.52 & -0.78 \\
\hline
\end{tabular}

\subsection{Analysis of Kenya's Monthly Inflation Trend}

To understand the trend Kenyan inflation rates over time, the Ordinary least squares method was used:

$$
\operatorname{INFRATE}(\mathrm{Y})=\mu_{0}+\mu_{1} \mathrm{t}
$$

Where, $\mu_{0}=$ Intercept of the regression line $\mu_{1}=$ slope of the OLS line

INFRATE=Monthly inflation rate

$\mathrm{t}=$ time in terms of months, $\mathrm{t}=1,2,3,4$.

$$
\begin{gathered}
\hat{\mu}_{1}=\frac{s_{t Y}}{s_{t t}}=\frac{\sum t_{i} Y_{i}-\frac{\sum t_{i} \sum Y_{i}}{n}}{\sum t_{i}^{2}-\frac{\left(t_{i}\right)^{2}}{n}} \\
\hat{\mu}_{1}=\frac{125084.5-\frac{14196 \times 1428.02}{168}}{1594684-\frac{14196^{2}}{168}}=\frac{4416.81}{395122}=0.0112 \\
\hat{\mu}_{0}=\frac{\sum Y_{i}-b_{1} \sum X_{i}}{n}=\frac{1428.02-0.0112 \times 14196}{168}=7.554
\end{gathered}
$$

Therefore the OLS equation of inflation rates on time in months is:

$$
\text { INFRATE }=7.554+0.0112 t_{i}
$$

The coefficient 0.0112 in the model implies that there was a positive trend in the rates of inflation. This implies that over time the Kenyan rate of inflation will be increasing.

In order to determine the significance of the positive trend, the t-test for trend was applied as shown below

HypothesesH0: $\hat{\mu}_{1}=0$

$\mathrm{H} 1: \hat{\mu}_{1} \neq 0$

Test statistic:

$$
\mathrm{T}_{0}=\frac{\widehat{\mu}_{1}}{\mathrm{~S}_{\mathrm{e}}\left(\widehat{\mu}_{1}\right)}
$$

Decision Criteria: Reject $\mathrm{H}_{0}$ if the calculated $\mathrm{t}$ value $\left(\mathrm{T}_{0}\right)$ is greater than the table value at $\propto / 2$ and (n-2) degrees of freedom $\left(t_{0.025,166}\right)$

Computations:

$$
\begin{gathered}
\mathrm{S}_{\mathrm{e}}\left(\hat{\mu}_{1}\right)=\sqrt{\frac{\widehat{\sigma}^{2}}{\mathrm{~S}_{\mathrm{tt}}}} \\
S S T=\sum \mathrm{Y}_{\mathrm{i}}^{2}-\mathrm{nY^{-2 } =} 16200.48-168 \times 8.5001^{2}=4062.2
\end{gathered}
$$

$\mathrm{SSE}=\mathrm{SST}-\hat{\mu}_{1} \mathrm{~S}_{\mathrm{tY}}=4062.2-0.0112 \times 4416.81=4012.73$ 


$$
\begin{gathered}
\widehat{\sigma}^{2}=\frac{\mathrm{SEE}}{\mathrm{n}-2}=\frac{4012.73}{168-2}=24.173 \\
\mathrm{~S}_{e}\left(\hat{\mu}_{1}\right)=\sqrt{\frac{\widehat{\sigma}^{2}}{\mathrm{~S}_{\mathrm{tt}}}}=\sqrt{\frac{24.173}{395122}}=0.0000612 \\
T_{0}=\frac{0.0112}{0.0000612}=183.01
\end{gathered}
$$

From the $\mathrm{t}$ tables, $\mathrm{t}_{\frac{\alpha}{2}, \mathrm{n}-\mathrm{p}}=\mathrm{t}_{0.025,166}=1.960$

Since $\mathrm{T}_{0}(183.01)>\mathrm{t}_{0.025,166}(1.960)$, we reject $\mathrm{H} 0$ and conclude that $\mu_{1}$ is significantly different from zero. We therefore conclude that there is a significant positive trend in Kenya's monthly inflation rates. The presence of trend in the data implies that the inflation data is non-stationary. This is also observed in the time series trend plot in figure 1 below.

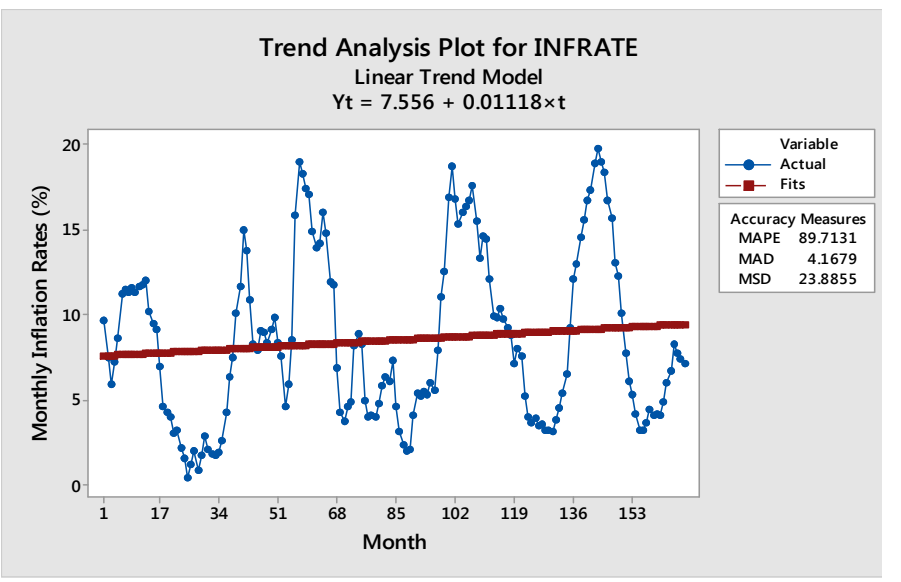

\subsection{Building a Multiplicative Seasonal ARIMA}

Anderson Darling (AD) goodness of fit test for normal distribution is $2.902 \quad(\mathrm{P}<0.005)$ while for lognormal distribution was $1.472(\mathrm{P}<0.005)$. After the Box-Cox Transformation the $\mathrm{AD}$ value was $0.983(\mathrm{P}=0.013)$ while after the Johnson Transformation the $\mathrm{AD}$ value was 0.461 $(\mathrm{P}=0.256)$. Based on the $\mathrm{AD}$ values the best-fitting distribution for Kenya's inflation data is a normal distribution after the Johnson Transformation. Johnson transformation function for the data was given as:

$$
\mathrm{Z}=0.554878+0.847254 \times \operatorname{Ln}\left\{\frac{(\mathrm{X}-0.330461)}{(21.5496-\mathrm{X})}\right\}
$$

Where $\mathrm{X}$ is the observed value of the inflation rates. This is illustrated in figure 2 below:

Figure 1. Trend analysis plot for Kenya's Inflation rate.

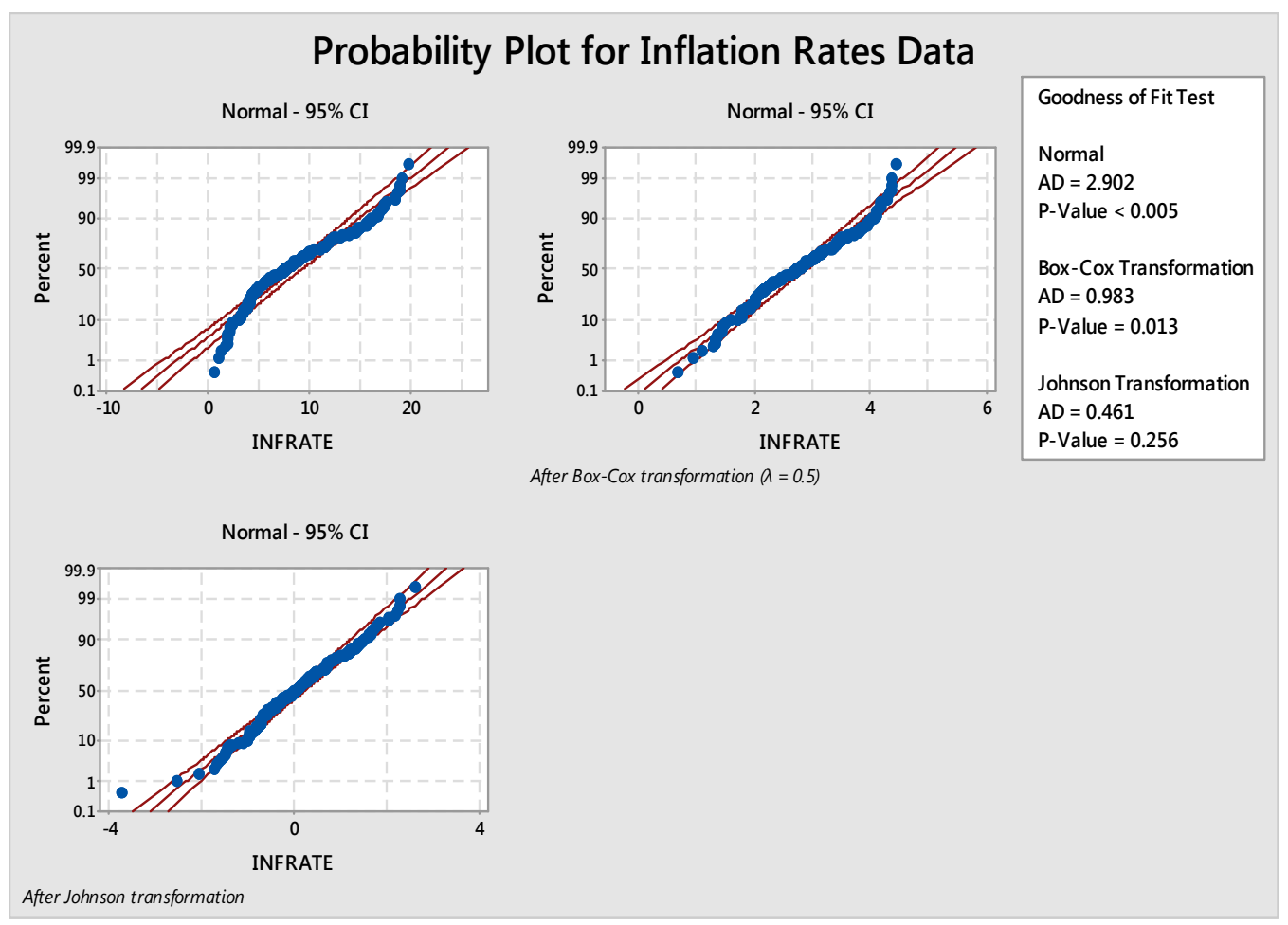

Figure 2. probability distribution plots for inflation rates data. 


\subsection{Model Identification}

From figure 1 it was established that the data was non-stationary. The time series plot after first difference as shown in figure 3 below show that the data fluctuates about a central value hence stationary.

This is further illustrated in the trend plot in figure 4 below in which the trend is neither increasing nor decreasing an indication of stationarity in mean. This implies that the no-seasonal differences required to make the data stationary are 1 i.e. $\mathrm{d}=1$

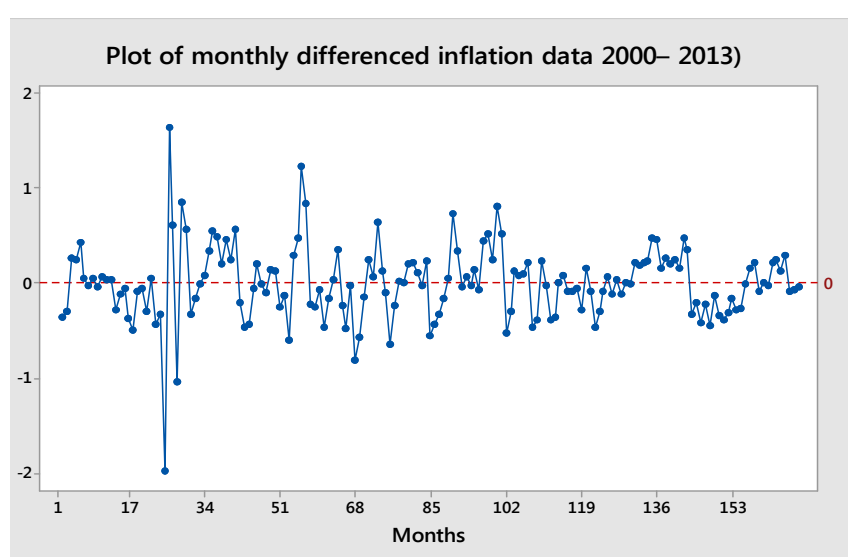

Figure 3. Plot of differenced inflation data.

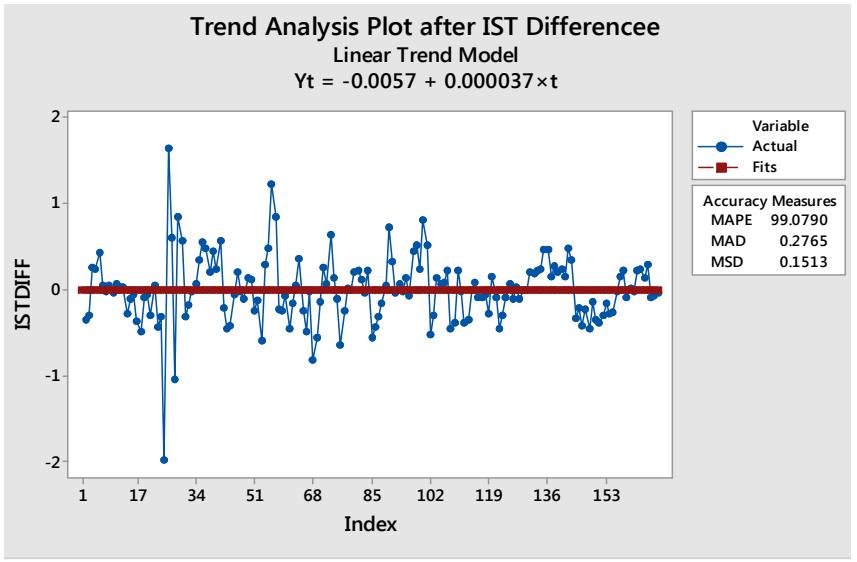

Figure 4. Time Series Plot of Monthly Differenced inflation data.

Further, the Augmented Dick-Fuller (ADF) test for Stationary as shown in Table2 below confirms the existence of unit root under the situation where either a constant or constant with linear trend were included in the tests.

Table 2. ADF unit root test for inflation series in its level form.

\begin{tabular}{llll}
\hline & Stat. & P-Value & C.V. \\
\hline No Constant & -1.7 & $8.1 \%$ & -2.0 \\
Constant Only & -3.8 & $7.6 \%$ & -2.9 \\
Constant Only & -3.9 & $5.3 \%$ & -1.0 \\
\hline
\end{tabular}

Since the series is non-stationary at the non-seasonal level, it makes it necessary for first non-seasonal differencing of the series to render it stationary. Considering the first non-seasonal differenced series, the ADF test results as shown in Table 3 show that the p-values were less than 5\% level of significance hence we fail to reject the null hypothesis that the first differenced series is stationary thus confirming the non-existence of unit root under the situation where either a constant or both constant and linear trend were included in the test. Therefore, the difference order should be at least one at non-seasonal level.

Table 3. ADF unit root test for inflation series after $1^{\text {st }}$ Difference.

\begin{tabular}{llll}
\hline & Stat. & P-Value & C.V. \\
\hline No Constant & -7.2 & $0.1 \%$ & -2.0 \\
Constant Only & -7.1 & $0.1 \%$ & -3.0 \\
Constant Only & -7.1 & $0.0 \%$ & -1.6 \\
\hline
\end{tabular}

The ACF plot as shown in Figure 5 slightly dies down in a sine wave fashion and the PACF plot as shown in Figure 6 tails at lag 1. Therefore an AR (1)model is suspected

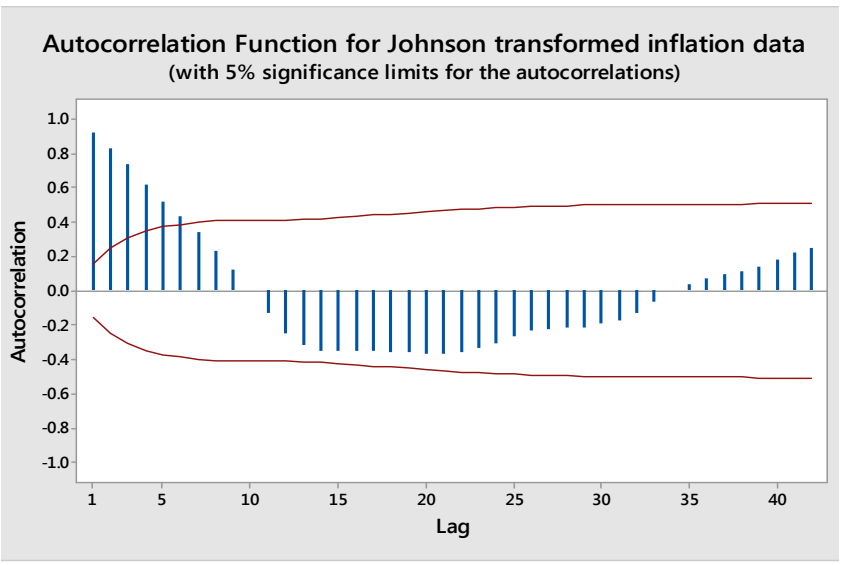

Figure 5. ACF for Johnson Transformed inflation data.

From figure 6 below, the PACF spike at lag 1, suggesting that a non-seasonal moving average of order 1 .

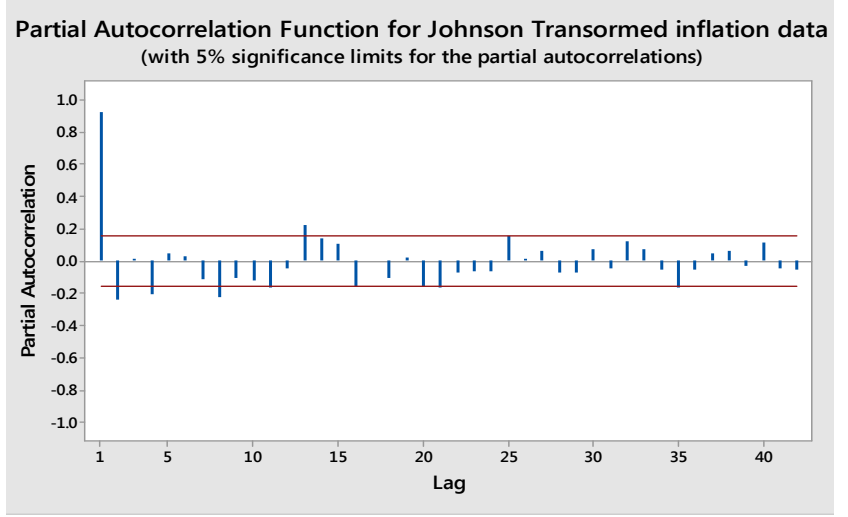

Figure 6. PACF for Johnson Transformed inflation data.

After first difference the ACF in figure 7 below shows that the ACF spikes at lag 12 indicating the presence of seasonal moving average $\operatorname{SMA}(12)$ hence $\mathrm{Q}=1$ 


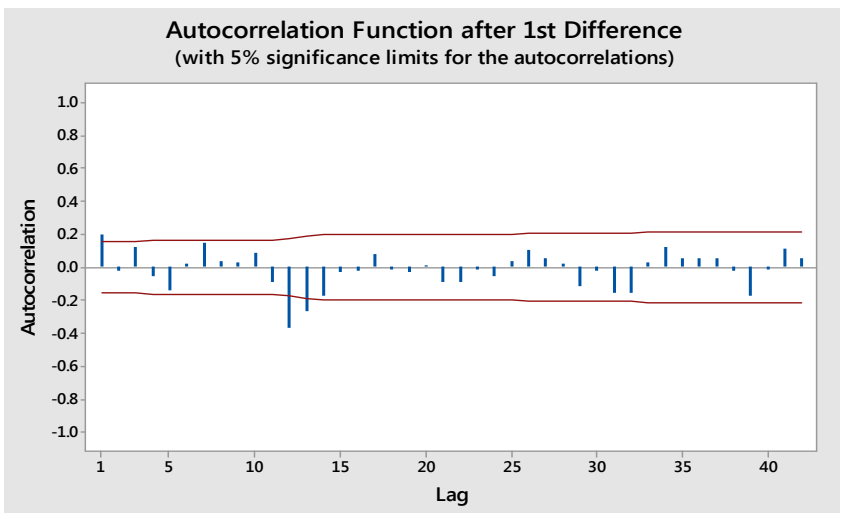

Figure 7. ACF after $1^{\text {st }}$ Difference.

The PACF of the differenced data as shown in figure 8 below shows that it spikes at seasonal lag 12 and drop to zero for other seasonal lags suggesting that and $\mathrm{P}=1$

Therefore, the seasonal part of the SARIMA model would be $(\mathrm{P}, \mathrm{D}, \mathrm{Q})=(1,0,1)_{12}$. Thus $\operatorname{ARIMA}(1,1,1)(1,0,1)_{12}$ is suggested as the probable model for the inflation data at both the non-seasonal and the seasonal levels.

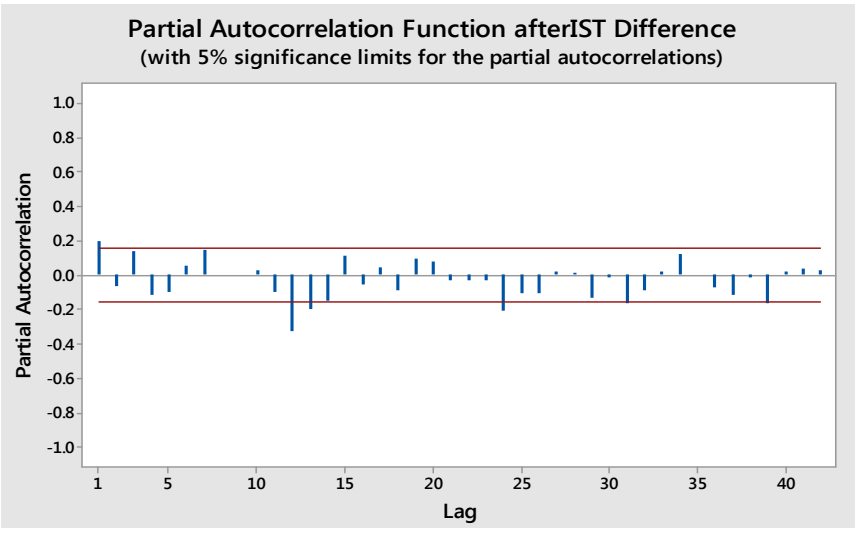

Figure 8.PACF after $1^{\text {st }}$ Difference.

By use AIC and BIC values Five tentative ARIMA models are tested for the inflation data series and the corresponding values for the models are presented in Table 4 below

The model ARIMA $(1,1,1)(1,0,1)_{12}$ was identified as the best model since it has the lowest AIC and BIC values of 172.541 and 182.652 respectively. The model indicators are $p$
$=0, d=1, q=1, P=1, D=0$ and $Q=1$ with $s=12$. This implies that the model suggested for Kenya's monthly inflation is a seasonal ARIMA model (SARIMA) of the form SARIMA(1, 1, 1) $(1,0,1)_{12}$.

Table 4. AIC and BIC Values of selected models.

\begin{tabular}{lll}
\hline ARIMA model & AIC Value & BIC value \\
\hline ARIMA $(0,1,1)(1,1,1)_{12}$ & 175.211 & 190.395 \\
ARIMA $(1,1,0)(1,1,1)_{12}$ & 172.787 & 184.535 \\
ARIMA $(1,1,1)(1,0,1)_{12}$ & 172.541 & 182.652 \\
ARIMA $(0,1,0)(1,1,1)_{12}$ & 173.541 & 184.421 \\
\hline
\end{tabular}

\subsection{Parameter Estimation}

The suggested model has four parameters whose estimations based on the Maximum Likelihood Estimation approach are given in the Table 5 below.

Table 5. Final Estimates of Parameters for SARIMA $(1,1,1)(1,0,1)_{12}$.

\begin{tabular}{lllll}
\hline Type & Coef & SE Coef & T & P \\
\hline AR1 & -0.6767 & 0.1737 & -3.90 & 0.000 \\
SAR12 & 0.2518 & 0.1232 & 2.40 & 0.043 \\
MA1 & -0.8165 & 0.1349 & -6.05 & 0.000 \\
SMA12 & 0.7577 & 0.0854 & 8.87 & 0.000 \\
\hline
\end{tabular}

In checking whether the parameters of the models have significant contribution which can provide the best forecast, the t-test values were used. The estimates of autoregressive, seasonal autoregressive, moving average and the seasonal moving average parameters were $-0.6767(\mathrm{t}=-3.90, \mathrm{p}<0.05)$, $0.2518(\mathrm{t}=2.40, \mathrm{p}<0.05),-0.8165(\mathrm{t}=-6.05, \mathrm{p}<0.05)$ and 0.7577 $(\mathrm{t}=8.87, \mathrm{p}<0.05)$ respectively. Based on $95 \%$ confidence level, the study concludes that all the coefficients of the $\operatorname{SARIMA}(1,1,1)(1,0,1)_{12}$ model are significantly different from zero.

The general form of the model as suggested by the results in Table 4 is:

$$
\begin{gathered}
\phi_{1}(B) \Phi_{1}\left(B^{12}\right)(1-B)\left(1-B^{12}\right)^{0} X_{t}=\theta_{1}(B) \Theta_{1}\left(B^{12}\right) e_{t} \\
(1-\phi B)\left(1-\Phi B^{12}\right)(1-B) X_{t}=(1-\theta B)\left(1-\Theta B^{12}\right) e_{t}
\end{gathered}
$$

Which expands to:

$$
\begin{gathered}
X_{t}-(1+\emptyset) X_{t-1}+\emptyset X_{t-2}-\Phi X_{t-12}+(\phi+\phi \Phi) X_{t-13}+\phi \Phi X_{t-14}=e_{t}-\theta e_{t-1}-\Theta e_{t-12}+\theta \Theta e_{t-13} \\
X_{\mathrm{t}}=(1+\emptyset) X_{\mathrm{t}-1}-\emptyset \mathrm{X}_{\mathrm{t}-2}+\Phi X_{\mathrm{t}-12}-(\phi+\phi \Phi) \mathrm{X}_{\mathrm{t}-13}-\phi \Phi \mathrm{X}_{\mathrm{t}-14}+\mathrm{e}_{\mathrm{t}}-\theta \mathrm{e}_{\mathrm{t}-1}-\Theta \mathrm{e}_{\mathrm{t}-12}+\theta \Theta \mathrm{e}_{\mathrm{t}-13}
\end{gathered}
$$

Substituting the values of $\phi=-0.6767 \Phi=0.2518, \theta=-0.8165$ and $\Theta=0.7577$ the model simplifies to:

$X_{t}=0.2518 X_{t-12}+0.3233 X_{t-1}+0.6767 X_{t-2}-0.0814 X_{t-13}-0.1704 X_{t-14}+e_{t}+0.8165 e_{t-1}-0.7577 e_{t-12}-0.6187 e_{t-13}$

The model shows that this month's rate of inflation depends on

i. the inflation rate in the same month of the previous year,

ii. a trend component determined by the difference between the sum of previous two month's values and the sum of last year's previous two month's values

iii. the effects of the residual terms of periods $t, t-1, t-12$ and t-13 
4.6. Diagnostics Checks of the Identified SARIMA $(1,1,1)$ $(1,0,1)_{12}$ Model

Table 6. Modified Box-Pierce (Ljung-Box) Chi-Square statistic.

\begin{tabular}{lllll}
\hline Lag & $\mathbf{1 2}$ & $\mathbf{2 4}$ & $\mathbf{3 6}$ & $\mathbf{4 8}$ \\
\hline Chi-Square & 10.5 & 27.3 & 41.4 & 60.2 \\
DF & 8 & 20 & 32 & 44 \\
P-Value & 0.233 & 0.126 & 0.124 & 0.053 \\
\hline
\end{tabular}

The p-values for the Ljung-Box statistic in Table 6 above all clearly exceed $5 \%$ for all lag orders, indicating that there is no significant departure from white noise for the residuals. The
Ljung - Box statistics also show overwhelming evidence that the residuals are independent implying the model fits the data well

\subsection{Forecast Results by $\operatorname{SARIMA}(1,1,1)(1,0,1)_{12}$ Model}

Table 7 below summarizes 12 months upfront inflation forecast from January 2014 to December 2014 with $95 \%$ confidence interval. The results show that there is a wide confidence interval indicating a high volatility in the inflation data which can be due to factors such as money supply, exchange rates depreciation and petroleum price increases.

Table 7. SARIMA $(1,1,1)(1,0,1)_{12}$ Forecasting Results.

\begin{tabular}{|c|c|c|c|c|c|}
\hline Month & Period & Forecast inflation rate & 95\% Lower confidence interval & 95\% upper confidence interval & Actual Inflation rate \\
\hline Jan. & 169 & 6.47 & 0.77 & 19.14 & 7.21 \\
\hline Feb. & 170 & 6.57 & 0.80 & 19.22 & 6.86 \\
\hline Mar. & 171 & 6.67 & 0.78 & 19.22 & 6.27 \\
\hline Apr. & 172 & 6.78 & 0.79 & 19.24 & 6.41 \\
\hline May & 173 & 6.82 & 0.82 & 19.29 & 7.30 \\
\hline Jun. & 174 & 7.03 & 0.88 & 19.36 & 7.39 \\
\hline Jul. & 175 & 7.12 & 0.91 & 19.41 & 7.67 \\
\hline Sep. & 177 & 7.25 & 0.92 & 19.45 & 6.60 \\
\hline Oct. & 178 & 7.23 & 0.91 & 19.45 & 6.43 \\
\hline Nov. & 179 & 7.17 & 0.90 & 19.46 & 6.09 \\
\hline Dec. & 180 & 7.32 & 0.91 & 19.14 & \\
\hline
\end{tabular}

\section{Conclusions and Recommendations}

The first objective of the study sought to analyze the trend of inflation rates in Kenya. The study established some monotonic trend in the Kenya's inflation rates.

The second objective sought to identify the Multiplicative Seasonal ARIMA model that can best be used to forecast Kenya's inflation rates. Box-Jenkins Seasonal Autoregressive Integrated Moving Average (SARIMA) was employed to analyze monthly inflation rates of Kenya from January 2000 to December 2013. Before the modelling, examination of the data revealed that it fit a normal distribution after the Johnson Transformation. The data was non-stationary at non-seasonal levels. However, after first difference, the data became stationary. By observing the ACF and PACF, SARIMA (1, 1, 1) $(1,0,1) 12$ was identified as one of the tentative models.

The model had the least AIC and BIC values and thus was selected as the best fitting model.

The third objective sought to estimate inflation in the next twelve (12) months of 2014. The forecast values established were within the confidence intervals. However, the Confidence intervals became wider as the time period increased. Based on this it was concluded that there was high volatility in the inflation data hence the SARIMA $(1,1$, 1)(1,0,1)12 model could be applied for short term forecasting. The forecast results revealed a slow increasing pattern of inflation rates in the 12 months of 2014. In light of the forecasted results, policy makers should develop more appropriate economic and monetary policies in order to combat such increase in inflation rates.

\section{Appendix}

Kenya's Monthly Inflation Rates (2000:1 - 2013:12)

\begin{tabular}{|c|c|c|c|c|c|c|c|c|c|c|c|c|c|c|}
\hline & 2000 & 2001 & 2002 & 2003 & 2004 & 2005 & 2006 & 2007 & 2008 & 2009 & 2010 & 2011 & 2012 & 2013 \\
\hline Jan & 9.63 & 11.97 & 0.46 & 6.37 & 9.14 & 14.87 & 8.15 & 4.63 & 7.93 & 13.33 & 7.52 & 5.42 & 18.31 & 3.67 \\
\hline $\mathrm{Feb}$ & 7.52 & 10.17 & 1.20 & 7.44 & 9.85 & 13.94 & 8.89 & 3.12 & 11.04 & 14.62 & 5.18 & 6.54 & 16.70 & 4.45 \\
\hline Mar & 5.90 & 9.46 & 2.03 & 10.12 & 8.32 & 14.15 & 8.26 & 2.31 & 12.53 & 14.44 & 3.97 & 9.19 & 15.61 & 4.11 \\
\hline Apr & 7.20 & 9.10 & 0.86 & 11.64 & 7.57 & 16.02 & 4.94 & 2.00 & 16.83 & 12.10 & 3.66 & 12.05 & 13.06 & 4.14 \\
\hline May & 8.60 & 6.94 & 1.71 & 14.92 & 4.65 & 14.78 & 3.99 & 2.09 & 18.70 & 9.88 & 3.88 & 12.95 & 12.22 & 4.05 \\
\hline Jun & 11.21 & 4.61 & 2.85 & 13.74 & 5.94 & 11.92 & 4.06 & 4.05 & 16.79 & 9.86 & 3.49 & 14.48 & 10.05 & 4.91 \\
\hline Aug & 11.31 & 4.03 & 1.81 & 8.27 & 15.80 & 6.87 & 4.81 & 5.19 & 15.98 & 9.76 & 3.22 & 16.67 & 6.09 & 6.67 \\
\hline Sep & 11.59 & 3.08 & 1.78 & 7.89 & 18.96 & 4.27 & 5.79 & 5.45 & 16.32 & 9.19 & 3.21 & 17.32 & 5.32 & 8.29 \\
\hline Oct & 11.28 & 3.21 & 1.89 & 9.08 & 18.29 & 3.72 & 6.31 & 5.32 & 16.70 & 8.80 & 3.18 & 18.91 & 4.14 & 7.76 \\
\hline Nov & 11.63 & 2.15 & 2.57 & 8.97 & 17.40 & 4.64 & 6.13 & 5.98 & 17.56 & 7.14 & 3.84 & 19.72 & 3.25 & 7.36 \\
\hline Dec & 11.78 & 1.60 & 4.25 & 8.35 & 17.08 & 4.91 & 7.32 & 5.60 & 15.48 & 8.02 & 4.51 & 18.93 & 3.20 & 7.15 \\
\hline
\end{tabular}

Source: Kenya Bureau of Statistics 


\section{References}

[1] Akaike, H. (1974). A New Look at the Statistical Model Identification. IEEE Transactions on Automatic Control 19 (6): 716-723.

[2] Akofio-Sowah (2009) Akofio-Sowah, N, (2009).Is there a link between Exchange Rate pass-through and the monetary regime: Evidence from Sub-Saharan Africa and Latin America. International Atlantic Economic Society. Available: http://www.springerlink.com

[3] Box, G. E. P and Jenkins, G.M., (1976). "Time series analysis: Forecasting and control," Holden-Day, San Francisco.

[4] Buckman A. and Mintah A. (2013). An Autoregressive Integrated Moving Average (ARIMA) Model For Ghana's Inflation (1985 - 2011).Mathematical Theory and Modeling Vol.3, No.3, 2013. www.iiste.org

[5] Dickey, D.A. \& Fuller, W.A. (1981). Likelihood Ratio Statistics for Autoregressive Time Series with a Unit Root. Econometrica, 49(4), 1057-1072.

[6] Fisher, S., Sahay, R.\&Vegh, C. (2002). "Modern Hyper-and High Inflation". Journal of Economic Literature,. 40, 837-80

[7] Fritzer, F., Gabriel, M. and Johann, S. (2002). "Forecasting Austrian HICP and its Components using VAR and ARIMA Models," Working Papers 73, Oesterreichische National bank (Austrian Central Bank).

[8] Kwiatkowski, D., Phillips, P. C. B., Schmidt, P. \& Shin, Y. (1992): Testing the Null Hypothesis of Stationarity against the Alternative of a Unit Root. Journal of Econometrics 54, 159-178.

[9] Mishkin, F. (2008).Exchange Rate Pass-through and Monetary Policy

[10] Otu, A., Osuji, G., Opara, J., Mbachu, H. and Iheagwara A. (2014). Application of Sarima Models in Modelling and Forecasting Nigeria's Inflation Rates. American Journal of Applied Mathematics and Statistics, 2014, Vol. 2, No. 1, 16-28

[11] Rotich, H., Kathanje, M \&Maana, I. (2007). A monetary policy reaction function for Kenya. Paper Presented During the 13th Annual African Econometric SocietyConference in Pretoria, South Africa from 9th to 11th July 2008.

[12] Stokes, G. (2009). FA news on line South Africa's premier financial and advisory news and information portal.

[13] Webster, D. (2000). Webster's New Universal Unabridged Dictionary. Barnes \& Noble Books, New York 